\title{
A decision rule based on goal programming and one-stage models for uncertain multi-criteria mixed decision making and games against nature
}

\author{
Helena Gaspars-Wieloch ${ }^{1, \dagger}$ \\ ${ }^{1}$ Department of Operations Research/Poznan University of Economics and Business \\ Al. Niepodleglosci 10, 61-875 Poznan, Poland \\ E-mail: 〈helena.gaspars@ue.poznan.pl〉
}

\begin{abstract}
This paper is concerned with games against nature and multi-criteria decision making under uncertainty along with scenario planning. We focus on decision problems where a deterministic evaluation of criteria is not possible. The procedure we propose is based on weighted goal programming and may be applied when seeking a mixed strategy. A mixed strategy allows the decision maker to select and perform a weighted combination of several accessible alternatives. The new method takes into consideration the decision maker's preference structure (importance of particular goals) and nature (pessimistic, moderate or optimistic attitude towards a given problem). It is designed for one-shot decisions made under uncertainty with unknown probabilities (frequencies), i.e for decision making under complete uncertainty or decision making under strategic uncertainty. The procedure refers to one-stage models, i.e. models considering combinations of scenarios and criteria (scenario-criterion pairs) as distinct meta-attributes, which means that the novel approach can be used in the case of totally independent payoff matrices for particular targets. The algorithm does not require any information about frequencies, which is especially desirable for new decision problems. It can be successfully applied by passive decision makers, as only criteria weights and the coefficient of optimism have to be declared.
\end{abstract}

Keywords: uncertainty, multi-criteria decision making, goal programming, games against nature, mixed strategies, one-stage models, one-shot decisions

Received: October 13, 2016; accepted: February 7, 2017; available online: March 31, 2017

DOI: 10.17535 /crorr.2017.0004

\section{Introduction}

This contribution relates to multiple-criteria decision making for cases where criteria evaluations are uncertain. This topic has been investigated by many researchers because usually real decision problems contain numerous conflicting criteria and a deterministic evaluation of criteria is often impossible. Possible models,

$\dagger$ Corresponding author 
methods and tools used to support uncertain multi-criteria decision making are described for instance in [12] (e.g. models with scenarios, models using probabilities or probability-like quantities, models with explicit risk measures, models with fuzzy numbers). The method proposed in the article is designed for one-shot decision problems and multi-criteria decision making with scenario planning. The procedure may be applied to totally new decision problems where the frequency of particular scenarios is not known. We assume that criteria payoff matrices are independent, which entails the opportunity to analyze the uncertain multi-criteria problem as a one-stage model. The new approach enables one to select an optimal mixed strategy. The procedure takes into account decision makers' objective preferences (criteria weights) and their attitude towards risk (coefficient of optimism). The algorithm includes a stage where a set of events with the biggest subjective chance of occurrence (separately for each payoff matrix) is suggested. The last step consists in formulating and solving the optimization problem.

The paper is organized as follows. Section 2 deals with the main features of multicriteria DMU (decision making under uncertainty), scenario planning and 1-stage models. Section 3 presents a procedure that may be used as a tool in multi-criteria optimization under uncertainty for mixed strategy searching and 1-stage models. Section 4 provides a case study on the basis of the bi-criteria single-period newsvendor problem. Conclusions are gathered in the last Section. The paper is a continuation of several articles, where uncertain one-criterion procedures [16], [18], [22] and multi-criteria decision rules for 2-stage models [20], [24], [25] were investigated.

\section{Uncertain multi-criteria decision making and 1-stage models}

In connection with the necessity to solve decision problems with uncertain parameters, many diverse theories have been developed, e.g. probability theory [39], possibility theory [77], [9], uncertainty theory [43], [44]. Nevertheless, it is worth emphasizing that there is no unanimity in defining the notion of uncertainty [26].

According to the first approach, the decision maker (DM) may choose the appropriate alternative (decision, strategy, variant) under certainty (DMC - each parameter of the decision problem is deterministic), under risk (DMR), under partial information (DMPI), under complete uncertainty (DMCU) or under total ignorance (DMTI). In the case of DMR, DMPI and DMCU, possible scenarios (states of nature, events) are predicted by experts or by the decision maker. DMCU occurs when the probability of those states of nature is not known or when the DM does not want to make use of the estimated probability distribution. If the likelihood of particular scenarios is known and significant for the DM, we then turn our attention to DMR [31], [37], [38], [54], [59], [60], [64], [72]. DMPI is characterized by probability distributions not known completely [33], [73], which 
means that the DM knows only a) the order of scenarios or b) the intervals with possible probabilities for each scenario. DMTI deals with problems for which the DM is not able to define possible events. Uncertainty and risk were formally integrated in economic theory by [68].

Supporters of the second approach declare that uncertainty involves all situations with non-deterministic parameters (known, unknown or incompletely known probability distribution, lack of information about possible scenarios), while risk is related to the possibility that some bad (or other than predicted) circumstances will happen [8], [10], [14], [32], [53], [72].

Scientists stress that the definition of uncertainty varies depending on the scientific domain. In the theory of decision, uncertainty means a situation where particular decisions may lead to different consequences and the probability of events is not known (see the first approach). In economics, uncertainty is defined as a situation where alternatives may lead to different effects and the probability of scenarios is known or not known. However, in the latter case, some probabilitylike quantities are often estimated and applied (see the second approach).

Apart from two above approaches, we also refer to the Austrian Economic School which treats uncertainty as do decision theorists, i.e. a situation where the likelihood is not known. According to that approach, the mathematical probability of the occurrence of a given scenario is not known since probabilities (understood as frequencies) only concern repetitive events, meanwhile for the majority of real problems, the DM deals with non-repetitive events [67]. Uncertainty is not caused by the randomness of events (as held by main-stream economists) but is due to numerous factors, of which only some are known in the decision-making process.

In this paper, we rather treat uncertainty according to the third approach, but we name it "uncertainty with unknown probabilities/frequencies" (or complete uncertainty, strategic uncertainty) to be more precise. Nevertheless, the theory of economics is also partially applied in this research given that unknown initial probabilities will be replaced with secondary probability-like quantities.

In many situations, computing the likelihood may be difficult due to many discrepant definitions of probability [6], [15], [38], [39], [67], lack of historical data (for totally new decisions and events) [23], [33], lack of sufficient knowledge concerning particular states or the fact that the set of possible scenarios forecasted by experts in the scenario planning stage does not satisfy probability axioms (the sum of state probabilities should be equal to 1 , the whole sample space must be precisely defined), see [39]. People may even be unable to declare subjective probabilities they implicitly set probabilities in acting [4]. Additionally, according to Von Mises [67], the theory of probability can never lead to a definite statement concerning a single event (the probability of a single event cannot be presented numerically).

There are many classical and extended decision rules designed for multi-criteria decision making under uncertainty, e.g. [1], [2], [7], [8], [11], [13], [20], [24], [25], 
[28], [29], [34], [36], [40], [41], [42], [45], [48], [49], [50], [51], [56], [57], [58], [61], [62], [63], [65], [66], [71], [74], [75], [76], however the majority of the methods refer to probability calculus. Hence, those contributions are not directly related to the topic investigated in this paper, since here we concentrate on totally new decision problems for which frequencies are not known.

Many existing procedures allow us to search for an optimal pure strategy, others are designed for optimal mixed strategies. In the case of pure strategies, the DM chooses and completely executes only one decision. A mixed strategy implies that the DM selects and performs a weighted combination of several accessible alternatives, see e.g. bonds portfolio construction, cultivation of different plants [24], [52], [55], [60]. This paper will deal with the latter case.

Some rules can be applied when the DM intends to perform the selected strategy only once. Others are recommended for people considering multiple realizations of the chosen variant. In the first case, final solutions are called one-shot decisions; in the second case - multi-shot decisions. This paper focuses on one-shot decision problems.

According to [12], uncertainties become increasingly so complex that the elicitation of measures such as probabilities, belief functions or fuzzy membership functions becomes operationally difficult for DMs to comprehend and virtually impossible to validate. Therefore, in such contexts it is useful to construct scenarios that describe possible ways in which the future might unfold and to combine MDMU (multi-criteria decision making under uncertainty) with SP (scenario planning). The result of the choice made under uncertainty with scenario planning depends on two factors: which decision will be selected and which scenario will occur [24]. Instead of using probabilities, here we apply probabilitylike quantities, i.e. coefficients of optimism $(\beta)$ or pessimism $(\alpha)$, which allow us to take into account the DM's nature (attitude towards a given problem) and define the set of events with the biggest chance of occurrence. These parameters belong to interval $[0,1]$ and satisfy the condition $\alpha+\beta=1 . \alpha(\beta)$ tends to 0 (1) for extreme optimists (risk-prone behavior) and is close to 1 (0) for radical pessimists (risk-averse behavior). Coefficients of pessimism and optimism have been already used in decision rules described, for example, in [16], [17], [18], [19], [20], [21], [22], [23], [24], [25], [35], [54].

As mentioned before, the decision rule presented in this paper enables the DM to find an optimal mixed strategy, but it is worth emphasizing that the existing onecriterion and multi-criteria procedures for mixed strategies are related more to game theory, i.e. games between players [5], [27], [30], [46], [47], [69], [70], than to games against nature (which constitutes a neutral opponent). Therefore, devising an approach for uncertain multi-objective mixed decision making and games against nature seems vital and desirable [24], [63].

According to [12], [48] MDMU+SP models can be divided into two classes. The first class (A) includes 2-stage models in which evaluations of particular alterna- 
tives are estimated in respect of scenarios and criteria in two separate stages. Class A contains two subclasses: A-CS and A-SC. Subclass A-CS denotes a set of approaches that consider decisions separately in each scenario before, set a $n \times m$ table ( $n$ - number of decisions, $m$ - number of scenarios) and provide the aggregated (over attributes/criteria) performance of an alternative $D_{j}$ under scenario $S_{i}$. These evaluations are then aggregated over scenarios. In subclass A-SC, the order of aggregation is reversed - performances are generated across scenarios and measures are then calculated over the criteria. The second class (B) consists of one-stage procedures that consider all combinations of scenarios and attributes (scenario-criterion pairs) as distinct meta-criteria and use a chosen multiplecriteria approach for the transformed meta-matrix. There is currently no consensus on the best way to solve uncertain multi-goal problems [12], [20]. We should notice that subclass A-CS may only be applied to dependent payoff matrices. Hence, the number of scenarios ought to be the same for each criterion considered in the decision problem and evaluation $a_{i j}{ }^{k}$ can only be connected with evaluations $a_{i j}{ }^{1}, \ldots, \quad a_{i j}{ }^{k-1}, \quad a_{i j}{ }^{k+1}, \ldots, \quad a_{i j}{ }^{p-1}$ and $a_{i j}{ }^{p}$ (these values describe the performance of each criterion based on decision $D_{j}$ provided that scenario $S_{i}$ occurs) where $p$ is the number of criteria. On the other hand, subclass A-SC can merely be used for independent payoff matrices, which means that this time there is no relationship between criteria. The performance of particular targets may be analyzed totally separately since the number of states of nature can be different for each goal $\left(m_{1}, m_{2}, \ldots, m_{p}\right)$. In the second case, evaluation $a_{i j}{ }^{k}$ might be connected with any evaluation $a_{i j}{ }^{1}\left(i=1, \ldots, m_{1}\right)$, any evaluation $a_{i j}{ }^{2}\left(i=1, \ldots, m_{2}\right), \ldots$ and any evaluation $a_{i j}^{p}\left(i=1, \ldots, m_{p}\right)$. Those values describe the performance of each criterion based on decision $D_{j}$ and assuming that any scenario occurs for criteria $C_{1}, \ldots, C_{k-1}, C_{k+1}, \ldots, C_{p}[20]$. Now we can easily notice that one-stage models (i.e. class B) are also dedicated to independent payoff matrices. One-stage models in the context of uncertain multi-criteria mixed decision making and games against nature have not as yet been analyzed in the literature. Nevertheless, we would like to investigate this topic, as it gives us the opportunity to elaborate a faster procedure than the methods designed for subclass A-SC.

The discrete version (i.e. a set of alternatives is explicitly defined and discrete) of $\mathrm{MDMU}+\mathrm{SP}$ with independent payoff matrices consists of $n$ decisions $\left(D_{1}, \ldots, D_{j}\right.$, $\ldots, D_{n}$ ), each evaluated on $p$ criteria $C_{1}, \ldots, C_{k}, \ldots, C_{p}$ and $m_{k}$ mutually exclusive scenarios $\left(S_{1}^{k}, \ldots, S^{k}{ }_{i}, \ldots, S_{m k}^{k}\right)$ where $k=1, \ldots, p$. The problem can be presented by means of $p$ payoff matrices (one for each criterion) and $n \times\left(m_{1}+\ldots+m_{k}+\ldots+m_{p}\right)$ evaluations. Each payoff matrix contains $n \times m_{k}$ evaluations, say $a_{i j}{ }^{k}$, which denote the performance of criterion $C_{k}$ resulting from the choice of decision $D_{j}$ and the occurrence of scenario $S_{i}^{k}$. We assume that the distribution of payoffs related to a given decision is discrete. 


\section{Procedure for MDMU+SP, 1-stage models and optimal mixed strategies}

In this section, we will present a decision rule that supports multi-criteria decision making under complete uncertainty when searching for an optimal mixed strategy and on the assumption that the problem is analyzed as a 1-stage model. We assume that payoff matrices are independent and that, within each criterion, payoffs connected with a given decision constitute sequences of outcomes (not sets of outcomes). Thus, the position of a payoff in the column is not accidental, but strictly depends on the scenario. The problem associated with sequences of outcomes, but based on pure strategies and one-criterion analysis, has been investigated, for example, by [55]. We will notice that the procedure requires us to reduce the initial sets of potential scenarios to the sets of states of nature with the biggest subjective chance of occurrence. The suggested method consists of the following steps:

1) Given a set of potential decisions and payoff matrices for each criterion, define

an appropriate value of the parameter $\beta \in[0,1]$ according to your level of optimism and choose weights $w^{k}$ for each attribute $(k=1, \ldots, p)$ :

$$
\sum_{k=1}^{p} w^{k}=1
$$

2) If necessary, normalize the evaluations (use Equation (2) for maximized criteria and Equation (3) for minimized criteria) separately within each payoff matrix:

$$
\begin{aligned}
& a(n)_{i j}^{k}=\frac{a_{i j}^{k}-\min _{\substack{i=1, \ldots, m_{k} \\
j=1, \ldots, n}}\left\{a_{i j}^{k}\right\}}{\max _{\substack{i=1, \ldots, m_{k} \\
j=1, \ldots, n}}\left\{a_{i j}^{k}\right\}-\min _{\substack{i=1, \ldots, m_{k} \\
j=1, \ldots, n}}\left\{a_{i j}^{k}\right\}} \quad k=1, \ldots, p ; i=1, \ldots, m_{k} ; j=1, \ldots, n \\
& a(n)_{i j}^{k}=\frac{\max _{\substack{i=1, \ldots, m_{k} \\
j=1, \ldots, n}}\left\{a_{i j}^{k}\right\}-a_{i j}^{k}}{\max _{i=1, \ldots, m_{k}}\left\{a_{i j}^{k}\right\}-\min _{j=1, \ldots, n}\left\{a_{i=1, \ldots, m_{k}}^{k}\right\}} \quad k=1, \ldots, p ; i=1, \ldots, m_{k} ; j=1, \ldots, n
\end{aligned}
$$


3) Create a meta-matrix containing $n$ columns for each decision and $\left(m_{1}+\ldots+m_{k}+\ldots+m_{p}=R\right)$ rows for scenarios assigned to subsequent targets. Complete that matrix using $n \times\left(m_{1}+\ldots+m_{k}+\ldots+m_{p}\right)$ normalized evaluations.

4) Find $M^{*}$ (the maximum normalized value computed according to the max-max rule) and calculate $y^{*}$ which is the maximized minimum guaranteed normalized value computed on the basis of Wald's model (Equations 4-7):

$$
\begin{gathered}
y \rightarrow \max \\
\sum_{j=1}^{n} a(n)_{i j} x_{j} \geq y, \quad i=1, \ldots, R \\
\sum_{j=1}^{n} x_{j}=1 \\
x_{j} \geq 0, j=1, \ldots, n
\end{gathered}
$$

where $x_{j}$ is the share of alternative $D_{j}$ in the mixed strategy and $n$ stands for the number of decisions. Due to the existence of more than one criterion, value $M^{*}$ is usually unattainable.

5) Choose the set of scenarios with the biggest chance of occurrence $\left(S P S^{k}\right)$ for each criterion separately. This can be done in diverse ways, e.g. on the basis of the dominance cases and the coefficient of optimism [16], [22], [24], [25] or intuitively. The higher the value of $\beta$, the fewer scenarios should be considered. Let us denote the number of scenarios with the biggest chance of occurrence in each set $S P S^{k}$ by $m_{k}^{*}$. Reduce the initial meta-matrix to the most subjectively "probable" meta-matrix containing $n$ columns for each decision, $\left(m_{1}^{*}+\ldots+m_{k}^{*}+\ldots+\right.$ $\left.m_{p}^{*}=R^{*}\right)$ rows for scenarios and $n \times\left(m^{*}{ }_{1}+\ldots+m^{*}{ }_{k}+\ldots+m_{p}^{*}\right)=n \times R^{*}$ normalized evaluations.

6) Solve the optimization problem consisting of Equations (6)-(7) and (8)-(10):

$$
\frac{w^{1}}{m_{1}^{*}} \cdot \sum_{i \in S P S^{1}} \max \left\{g_{i}^{1}, 0\right\}+\ldots+\frac{w^{k}}{m_{k}^{*}} \cdot \sum_{i \in S P S^{k}} \max \left\{g_{i}^{k}, 0\right\}+\ldots+\frac{w^{p}}{m_{p}^{*}} \cdot \sum_{i \in S P S^{p}} \max \left\{g_{i}^{p}, 0\right\} \rightarrow \min
$$




$$
\begin{gathered}
\sum_{j=1}^{n} a(n)_{i j} x_{j}=r_{\beta}-g_{i}^{k}, \quad i=1, \ldots, R^{*} \\
r_{\beta}=\beta\left(M^{*}-y^{*}\right)+y^{*}
\end{gathered}
$$

Where $r_{\beta}$ is the expected level of the outcome dependent on $\beta$ (Equation 10) and $g^{k}{ }_{i}$ denotes the deviation from $r_{\beta}$ of the outcome achieved by the DM if scenario $S^{k}{ }_{i}$ occurs. Both sides of condition (9) present the true criterion performance obtained if the shares of a given mixed strategy equal $x_{1}, x_{2}, \ldots, x_{n}$ and scenario $S^{k}{ }_{i}$ takes place. The aim of the optimization model (Equation 8) is to minimize, within the reduced sets of scenarios, the sum of all positive deviations of the true payoffs from the expected one (similar to goal programming). Note that only positive deviations are disadvantageous since the expected outcome then exceeds the true result [18]. The optimal solution represents the multi-criteria mixed strategy reflecting the DM's level of optimism and considering his/her objective preferences. Let us call the described procedure $\beta$-MMDM/1, i.e. $\beta$ decision rule for multi-criteria mixed decision making and 1-stage models.

\section{Case study}

The method suggested in this paper will be illustrated by means of the following example. We analyze a bi-criteria single-period newsvendor problem (the onecriterion problem is described e.g. in [23], [26]). Usually, this issue is treated as a stochastic problem (with a known probability distribution) [3], [60], but in [26], [33] authors stress the necessity to investigate the topic as a strategic problem (with unknown probabilities). The newsvendor has 20 similar retail outlets (located in different places, but the distances between particular stores and the wholesaler business are nearly the same) where he intends to sell a totally new short-cycle product. He assumes that the quantity procured will be used solely to satisfy the demand during the current period. The demand for this product is not known in advance. He considers order $(q)$ and demand $(D)$ quantities between 1 and 5 boxes. The unit production/purchase cost of 1 box $\left(c_{1}\right)$ equals 5 , the selling price $\left(c_{2}\right)$ equals 9 and the discount price (price of leftover items) $c_{3}=2$, hence the unit profit from selling the product at price $c_{2}: b=c_{2}-c_{1}=4$ and the unit loss from selling it at price $c_{3}: s=c_{1}-c_{3}=3$. The newsvendor maximizes the total profit (e.g. in thousands of Euros) resulting from buying and selling the new product ( $1^{\text {st }}$ criterion dependent on the demand) and minimizes the cost of supply ( $2^{\text {nd }}$ criterion dependent on the supplying, storage, weather conditions). Note that the total profit does not include the cost of supply and is equal to $b \times q$ (for $q \leq D$ ) 
or $b \times D-s \times(q-D)$ when $q>D$. Payoff matrices are given in Table 1 (first values in each cell). The newsvendor intends to find an optimal mixed strategy, hence he is willing to order different quantities of the new product for particular retail outlets. Now, let us apply procedure $\beta-\mathrm{MMDM} / 1$ for the aforementioned problem.

\begin{tabular}{|l|c|c|c|c|c|}
\hline \multicolumn{1}{|c|}{ Crit. 1} & $A_{1}=1$ & $A_{2}=2$ & $A_{3}=3$ & $A_{4}=4$ & $A_{5}=5$ \\
\hline$S^{1}{ }_{1}=1$ & $4 / 0.43$ & $1 / 0.32$ & $-2 / 0.21$ & $-5 / 0.11$ & $-8 / 0.00$ \\
\hline$S^{1}{ }_{2}=2$ & $4 / 0.43$ & $8 / 0.57$ & $5 / 0.46$ & $2 / 0.36$ & $-1 / 0.25$ \\
\hline$S^{1}{ }_{3}=3$ & $4 / \underline{0.43}$ & $8 / \underline{0.57}$ & $12 / \underline{0.71}$ & $9 / \underline{0.61}$ & $6 / \underline{0.50}$ \\
\hline$S^{1}{ }_{4}=4$ & $4 / \underline{0.43}$ & $8 / \underline{0.57}$ & $12 / \underline{0.71}$ & $16 / \underline{0.86}$ & $13 / \underline{0.75}$ \\
\hline$S^{1}{ }_{5}=5$ & $4 / \underline{0.43}$ & $8 / \underline{0.57}$ & $12 / \underline{0.71}$ & $16 / \underline{0.86}$ & $20 / \underline{1.00}$ \\
\hline \multicolumn{1}{|c|}{ Crit. 2} & $A_{1}=1$ & $A_{2}=2$ & $A_{3}=3$ & $A_{4}=4$ & $A_{5}=5$ \\
\hline$S^{2}{ }_{1}$ & $0.5 / \underline{1.00}$ & $0.6 / \underline{0.96}$ & $0.7 / \underline{0.92}$ & $0.8 / \underline{0.87}$ & $0.9 / \underline{0.83}$ \\
\hline$S_{2}{ }_{2}$ & $1 / 0.79$ & $1.1 / 0.75$ & $1.2 / 0.71$ & $1.3 / 0.67$ & $1.4 / 0.62$ \\
\hline$S^{2}{ }_{3}$ & $2 / 0.37$ & $2.2 / 0.29$ & $2.5 / 0.17$ & $2.7 / 0.08$ & $2.9 / 0.00$ \\
\hline
\end{tabular}

Table 1: Criteria payoff matrices and normalized values (example), source prepared by the author.

First (step 1), we assume that the DM is a moderate optimist ( $\beta=0.7, \alpha=0.3)$ and that $w^{1}=0.6, w^{2}=0.4$. We normalize values (step 2 ) - they have the same units, but they are expressed in different scales, see Table 1 (second value in each cell). The meta-matrix (step 3) contains 5 columns (5 decisions), 8 rows (5 scenarios for the $1^{\text {st }}$ criterion and 3 scenarios for the $2^{\text {nd }}$ criterion) and 40 normalized values (we do not present it due to page limitations, but values in the meta-matrix are equal to normalized values from Table 1). Parameters $M^{*}$ and $y^{*}$ are equal to 1 and 0.375 (step 4). In step 5 we use the procedure suggested in [24], but other approaches are also possible, and we obtain $S P S^{1}=\left\{\mathrm{S}^{1}{ }_{3}, \mathrm{~S}_{4}{ }_{4}, \mathrm{~S}_{5}\right\}, S P S^{2}=\left\{\mathrm{S}_{1}{ }_{1}\right\}$. Now, the reduced meta-matrix contains 5 columns, only 4 rows and 20 normalized values (underlined, Table 1). In step 6 we solve the following model where $r_{\beta}=0.7(1-0.375)+0.375=0.812$, variables $x_{j}$ are non-negative and their sum equals 1 .

$$
\begin{gathered}
0.6 / 3 \cdot\left(\max \left\{g_{3}^{1}, 0\right\}+\max \left\{g_{4}^{1}, 0\right\}+\left\{g_{5}^{1}, 0\right\}\right)+0.4 \cdot \max \left\{g_{1}^{2}, 0\right\} \rightarrow \min \\
0.43 x_{1}+0.57 x_{2}+0.71 x_{3}+0.61 x_{4}+0.50 x_{5}=0.812-g_{3}^{1}
\end{gathered}
$$




$$
\begin{aligned}
& 0.43 x_{1}+0.57 x_{2}+0.71 x_{3}+0.86 x_{4}+0.75 x_{5}=0.812-g_{4}^{1} \\
& 0.43 x_{1}+0.57 x_{2}+0.71 x_{3}+0.86 x_{4}+1.00 x_{5}=0.812-g_{5}^{1} \\
& 1.00 x_{1}+0.96 x_{2}+0.92 x_{3}+0.87 x_{4}+0.83 x_{5}=0.812-g_{1}^{2}
\end{aligned}
$$

The optimal solution is as follows: $x_{1}=0 ; x_{2}=0 ; x_{3}=0.31 ; x_{4}=0.69 ; x_{5}=0$ and $g^{1}{ }_{3}=0.17 ; g^{1}{ }_{4}=0 ; g^{1}{ }_{5}=0 ; g^{2}{ }_{1}=-0.07$. Hence, if the optimal strategy is executed, for three scenarios: $\mathrm{S}_{4}^{1}, \mathrm{~S}_{5}^{1}, \mathrm{~S}^{2}$ it will be possible to gain at least the expected normalized value (dependent on $\beta$ ). The obtained variable values signify that for $31 \%$ of retail outlets (approximately 6 ) the order quantity should be equal to 3 boxes and for $69 \%(\approx 14)$ the order quantity should be equal to 4 . Note that the little change of optimal results $(31 \% \rightarrow 30 \%, 69 \% \rightarrow 70 \%)$ is required due to the discrete number of retail outlets, but it does not seriously affect the deviation values: $g^{1}=0.17 ; g^{1}{ }_{4}=0 ; g^{1}=0 ; g^{2}=-0.07$. As was mentioned above, the entire mixed strategy covers only one season.

\section{Conclusions}

The paper contains a description of a decision rule supporting multi-criteria decision making under uncertainty with unknown probabilities (frequencies). Its goal is to find an optimal mixed strategy (combination of pure strategies) which constitutes a one-shot decision (it is executed only once). The method is designed for games against nature. It is based on one-stage models. The final model formulated and solved in the last step of the algorithm is characteristic of weighted goal programming, but here only positive values of deviations are disadvantageous since the expected outcome then exceeds the true result. Advantages of applying that approach are as follows: 1) It does not require any information about probabilities, which is especially desirable in the case of new decision problems, 2) It takes into consideration the decision maker's preference structure and nature, but only criteria weights and the level of optimism are supposed to be declared - hence, the procedure may be successfully applied by passive decision makers, 3) It can be used in the case of totally independent payoff matrices for particular targets, 4) It is less time-consuming than procedures based on 2-stage models. The novel rule has been demonstrated on the basis of an illustrative example concerning the scenario-based bi-criteria newsvendor problem. In the future, it would be desirable to explore the uncertain multicriteria mixed decision making problem on the assumption that payoffs connected with particular decisions are presented as sets (not sequences) of outcomes, since in some real problems payoffs connected with particular investments depend on totally different scenarios (even within the framework of a given criterion). 


\section{Acknowledgement (funding)}

This work is supported by the National Science Center, Poland [grant number 2014/15/D/HS4/00771].

\section{References}

[1] Aghdaie, M. H., Zolfani, S. H., and Zavadskas E. K. (2013). Market segment evaluation and selection based on application of fuzzy AHP and COPRAS-G Methods. Journal of Business Economics and Management, 14(1), 213-233.

[2] Ben Amor, S., Jabeur, K., Martel, J. (2007). Multiple criteria aggregation procedure for mixed evaluations. European Journal of Operational Research., 181(3), 1506-1515.

[3] Bieniek, M. (2016). Bicriteria optimization in the newsvendor problem with exponentially distributed demand. Multiple criteria decision making (in print)

[4] Caplan, B. (2001). Probability, common sense, and realism: a reply to Hulsmann and Block. The Quarterly Journal of Austrian Economics, 4(2), 69-86.

[5] Czerwiński, Z. (1969). Matematyka na usługach ekonomii. Warsaw: Państwowe Wydawnictwo Naukowe.

[6] De Finetti, B. (1975). Theory of probability. A critical introductory treatment. London: Wiley.

[7] Dominiak, C. (2006): Multi-criteria decision aid under uncertainty. Multiple Criteria Decision Making' 05, 63-81.

[8] Dominiak, C. (2009). Multi-criteria decision aiding procedure under risk and uncertainty. Multiple Criteria Decision Making' 08, 61-88.

[9] Dubois, D., and Prade, H. (2001). Possibility theory, probability theory and multiple-valued logics: a clarification. Annals of Mathematics Artificial Intelligence., 32, 35-66.

[10] Dubois, D., and Prade, H. (2012). Gradualness, uncertainty and bipolarity: making sense of fuzzy sets. Fuzzy Sets and Systems, 192, 3-24.

[11] Durbach, I. N. (2014). Outranking under uncertainty using scenarios. European Journal of Operational Research, 232(1), 98-108.

[12] Durbach, I. N., and Stewart, T. J. (2012). Modeling uncertainty in multi-criteria decision analysis. European Journal of Operational Research, 223(1), 1-14.

[13] Eiselt, H. A., and Marianov, V. (2014). Multi-criteria decision making under uncertainty: a visual approach. International Transactions in Operational Research, 21(4), 525-540.

[14] Fishburn, P.C. (1984). Foundations of risk measurement. I. risk or probable loss. Management Science, 30, 396-406.

[15] Frechet, M. (1938). The diverse definitions of probability. Lecture at the fourth International Congress for the Unity of Science, Erkenntnis. 
[16] Gaspars-Wieloch, H. (2013). On a decision rule supported by a forecasting stage based on the decision maker's risk aversion, in L. Zadnik Stirn, J. Zerovnik, J. Povh, S. Drobne, A. Lisec (Eds.). "SOR'13 Proceedings, The $12^{\text {th }}$ International Symposium on Operational Research in Slovenia", 25-27 September 2013, Dolenjske Toplice, Slovenia, Slovenian Society INFORMATIKA, Section for Operational Research, 53-59.

[17] Gaspars-Wieloch, H. (2014a). A hybrid of the Hurwicz and Bayes rules in decision making under uncertainty [Propozycja hybrydy reguł Hurwicza i Bayesa w podejmowaniu decyzji w warunkach niepewności]. T. Trzaskalik (Ed.) „Modelowanie Preferencji a Ryzyko 2014. Studia Ekonomiczne. Zeszyty Naukowe Uniwersytetu Ekonomicznego w Katowicach" 178, Wydawnictwo Uniwersytetu Ekonomicznego w Katowicach, Katowice, 74-92 (in Polish).

[18] Gaspars-Wieloch, H. (2014b). On a decision rule for mixed strategy searching under uncertainty on the basis of the coefficient of optimism. Elsevier. Procedia - Social and Behavioral Sciences 110, 923-931.

[19] Gaspars-Wieloch, H. (2014c). Modifications of the Hurwicz's decision rules. Central European Journal of Operations Research 22(4), 779-794.

[20] Gaspars-Wieloch, H. (2014c). The use of a modification of the Hurwicz's decision rule in multi-criteria decision making under complete uncertainty. Business, Management and Education 12(2), 283-302.

[21] Gaspars-Wieloch, H. (2015a). Modifications of the omega ratio for decision making under uncertainty. Croatian Operational Research Review 6(1), 181194.

[22] Gaspars-Wieloch, H. (2015b). On a decision rule supported by a forecasting stage based on the decision maker's coefficient of optimism. Central European Journal of Operations Research 23(3), 579-594.

[23] Gaspars-Wieloch, H. (2015c). Innovative products and newsvendor problem under uncertainty without probabilities, in L. Zadnik Stirn, J. Zerovnik, M. Kljajic Borstnar, S. Drobne (Eds.). "SOR'15 Proceedings, The $13^{\text {th }}$ International Symposium on Operational Research in Slovenia", 23-25 September 2015, Bled, Slovenia, Slovenian Society INFORMATIKA, Section for Operational Research, 343-350.

[24] Gaspars-Wieloch, H. (2015d). A decision rule for uncertain multi-criteria mixed decision making based on the coefficient of optimism. Multiple Criteria Decision Making'15, University of Economics in Katowice, 32-47

[25] Gaspars-Wieloch, H. (2015e). O regule decyzyjnej wspierającej wielokryterialne poszukiwanie optymalnej strategii czystej w warunkach niepewności, Studia Ekonomiczne. Zeszyty Naukowe Uniwersytetu Ekonomicznego w Katowicach, University of Economics in Katowice, 2015, 42-61.

[26] Gaspars-Wieloch, H. (2016). Newsvendor problem under complete uncertainty: a case of innovative products. Central European Journal of Operations Research. DOI: $10.1007 / \mathrm{s} 10100-016-0458-3$. 
[27] Gilboa, I. (2009). Theory of decision under uncertainty. New York, Cambridge: Cambridge University Press.

[28] Ginevičius, R., and Zubrecovas, V. (2009). Selection of the optimal real estate investment project basing on multiple criteria evaluation using stochastic dimensions. Journal of Business Economics and Management, 10(3), 261-270.

[29] Goodwin, P., and Wright, G. (2001). Enhancing strategy evaluation in scenario planning: a role for decision analysis. Journal of Management Studies, 38(1), 116.

[30] Grigorieva, X. (2014). Multi-criteria coalitional model of decision-making over the set of projects with constant payoff matrix in the noncooperative game. Applied Mathematical Sciences 8(170), 8473-8479.

[31] Groenewald, M. E., and Pretorius, P. D. (2011). Comparison of decision making under uncertainty investment strategies with the money market. Journal of Financial Studies and Research. DOI: 10.5171/2011.373376

[32] Guney, S., and Newell, B.R. (2015). Overcoming ambiguity aversion through experience. Journal of Behavioral Decision Making, 28(2), 188-199.

[33] Guo, P. (2011). One-shot decision theory. IEEE Transactions on Systems, Man, and Cybernetics, Part A, 41(5), 917-926.

[34] Hopfe, C. J., Augenbroe, G. L. M., and Hensen J. L. M. (2013). Multi-criteria decision making under uncertainty in building performance assessment. Building and Environment 69, 81-90.

[35] Hurwicz, L. (1952). A criterion for decision making under uncertainty. Technical Report, 355. Cowles Commission.

[36] Janjic, A., Andjelkovic, A., and Docic, M. (2013). Multiple criteria decision making under uncertainty based on stochastic dominance. Proceedings of the 2013 International Conference on Applied Mathematics and Computational Methods in Engineering" 16-19 July 2013, Rhodes Island, Greece, 86-91.

[37] Kaplan, S., and Barish, N.N. (1967). Decision-making allowing for uncertainty of future investment opportunities. Management Sciences 13(10), 569-577.

[38] Knight, F. H. (1921). Risk, uncertainty, profit. Hart. Boston MA, Schaffner \& Marx, Houghton Mifflin Co.

[39] Kolmogorov, A. N. (1933). Grundbegriffe der Wahrscheinlichkeitsrechnung. Berlin: Julius Springer.

[40] Korhonen, A. (2001). Strategic financial management in a multinational financial conglomerate: a multiple goal stochastic programming approach. European Journal of Operational Research 128, 418-434.

[41] Lee, Y.-H. (2012). A fuzzy analytic network process approach to determining prospective competitive strategy in China: a case study for multinational biotech pharmaceutical enterprises. Journal of Business Economics and Management 13(1), 5-28. 
[42] Liu, Y., Fan, Z., and Hang, Y. (2011). A method for stochastic multiple criteria decision making based on dominance degrees. Information Sciences 181(19), 4139-4153.

[43] Liu, B. (2007). Uncertainty theory. 2nd ed. Berlin: Springer-Verlag.

[44] Liu, B. (2009). Some research problems in uncertainty theory. Journal of Uncertain Systems, 3(1), 3-10.

[45] Lo, M.C., and Michnik, J. (2010). An evaluation method based on multiattributes analysis with stochastic dominances for improving the information quality. International Journal of Information Systems for Logistics and Management 6, 25-30.

[46] Lozan, V., and Ungureanu, V. (2013). Computing the Pareto-Nash equilibrium set in finite multi-objective mixed-strategy games. Computer Science Journal of Moldova 21, 2(62), 173-203.

[47] Luce, R.D, and Raiffa H. (1957). Games and decisions. New York: Wiley.

[48] Michnik, J. (2013). Scenario planning+MCDA procedure for innovation selection problem. Foundations of Computing and Decision Sciences 38(3), 207220.

[49] Mikhaidov, L., and Tsvetinov, P. (2004). Evaluation of services using a fuzzy analytic hierarchy process. Applied Soft Computing Journal 5(1): 23-33.

[50] Montibeller, G., Gummer, H., and Tumidei, D. (2006). Combining scenario planning and multi-criteria decision analysis in practice. Journal of Multi-criteria Decision Analysis. Optimziation, Learning and Decision Support 14, 5-20.

[51] Nowak, M., Trzaskalik, T. (2015). An interactive approach to the stochastic multi-objective allocation problem. Croatian Operational Research Review 6(1), 293-304.

[52] Officer, R. R., and Anderson J. R. (1968). Risk, uncertainty and farm management decisions. Review of Marketing and Agricultural Economics, 36(01).

[53] Ogryczak, W., and Śliwiński T. (2009). On efficient WOWA optimization for decision support under risk. International Journal of Approximate Reasoning 50, 915-928.

[54] Perez, D.E, Hernandez, J.G., Garcia, M.J., and Hernandez, G.J. (2015). Hurwicz method modified and the Amplitude Model (TAM). In Delener et al. (Ed), GBATA2015 Reading book (pp. 559-566). USA:GBATA.

[55] Puppe, C., and Schlag, K. (2009). Choice under complete uncertainty when outcome spaces are state dependent, Theory and Decision, 66, 1-16.

[56] Ram, C., Montibeller, G., and Morton, A. (2010). Extending the use of scenario planning and MCDA for the evaluation of strategic options. Journal of Operational Research Society 62(5), 817-829.

[57] Ramík, J., Hanclova, J., Trzaskalik, T., and Sitarz, S. (2008). Fuzzy multiobjective methods in multistage decision problems. Multiple Criteria Decision Making '07, 186-201. 
[58] Ravindran, A. R. (2008). Operations research and management science handbook. Boca Raton, London, New York, CRS Press.

[59] Render, B., Stair, R. M., and Hanna, M. E. (2006), Quantitative analysis for management. Upper Saddle River, New Jersey: Pearson Prentice Hall.

[60] Sikora, W. (ed) (2008). Badania Operacyjne (Operations research). Warsaw: Polskie Wydawnictwo Ekonomiczne (in Polish).

[61] Stewart, T. J. (2005). Dealing with uncertainties in MCDA, multiple criteria decision analysis: state of the art surveys. International Series in Operations Research \& Management Science, 78, 445-466.

[62] Suo, M. Q., Li, Y. P., and Huang, G. H. (2012). Multicriteria decision making under uncertainty: an advanced ordered weighted averaging operator for planning electric power systems. Engineering Applications of Artificial Intelligence, 25(1), $72-81$.

[63] Troutt, M.D., and Pettypool, M.D. (1989). On the role of mixed strategies in the elementary decision analysis and related Decision-Support-System Treatments. Journal of the Operational Research Society 40(6), 571-579.

[64] Trzaskalik, T. (2008). Wprowadzenie do badań operacyjnych z komputerem (Introduction to operations research with computer). 2nd ed. Warsaw: Polskie Wydawnictwo Ekonomiczne. (in Polish)

[65] Tsaur, S., Chang, T., and Yen, C. (2002). The evaluation of airline service quality by fuzzy MCDM. Tourism Management, 23(2), 107-115.

[66] Urli, B., and Nadeau, R. (2004). PROMISE/scenarios: an interactive method for multiobjective stochastic linear programming under partial uncertainty. European Journal of Operational Research 155(2), 361-372.

[67] Von Mises, L. (1949). Human action: a treatise on economics. Yale University Press.

[68] Von Neumann, J., and Morgenstern, O. (1944). Theory of games and economic behavior. Princeton, New York: Princeton University Press.

[69] Voorneveld, M., Grahn, S., and Dufwenberg, M. (2000). Ideal equilibria in noncooperative multicriteria games. Mathematical Methods of Operations Research, $52,65-77$.

[70] Voorneveld, M., Vermeulen, D., and Borm, P. (1999). Axiomatizations of Pareto equilibria in multicriteria games. Games and Economic Behavior 28, 146-154.

[71] Wang, Y., and Elhag, T. (2006). Fuzzy TOPSIS method based on alpha level sets with an application to bridge risk assessment. Expert Systems with Applications 31(2), 309-319.

[72] Waters, D. (2011). Supply chain risk management. Vulnerability and resilience in logistics. Kogan Page.

[73] Weber, M. (1987). Decision making with incomplete information. European Journal of Operational Research 28, 44-57. 
[74] Wojewnik, P., and Szapiro, T. (2010) Bireference procedure FBI for interactive multicriteria optimization with fuzzy coefficients. Central European Journal of Economic Modeling and Econometrics 2, 169-193.

[75] Xu, R. (2000). Fuzzy least-squares priority method in the analytic hierarchy process. Fuzzy Sets and Systems 112(3), 395-404.

[76] Yu, C. (2002). A GP-AHP method for solving group decision-making fuzzy AHP problems. Computers and Operations Research 29(14), 1969-2001.

[77] Zadeh, L. (1978). Fuzzy sets as the basis for a theory of possibility. Fuzzy Sets and Systems, 1, 3-28. 